\section{PSQ-143 PREVALENCE OF POTENTIALLY INAPPROPRIATE PRESCRIPTIONS IN INSTITUTIONALISED AND NON- INSTITUTIONALISED ELDERLY PATIENTS}

${ }^{1} \mathrm{C}$ Moncada Monte*, ${ }^{2} \mathrm{~B}$ Montero Llorente, ${ }^{1} \mathrm{AM}$ Cordero Cruz, ${ }^{2} \mathrm{M}$ Muñoz García, ${ }^{2} \mathrm{~T}$ Bermejo Vicedo, ${ }^{2} \mathrm{E}$ Delgado Silveira. ${ }^{1}$ Francisco de Vitoria University, Faculty of Pharmacy, Madrid, Spain; ${ }^{2}$ Hospital Ramon Y Cajal, Pharmacy Department, Madrid, Spain

10.1136/ejhpharm-2019-eahpconf.576

Background Potentially inappropriate prescriptions (PIP) cause an elevated number of hospital admissions in multipathological polymedicated geriatric patients. An important percentage of this population lives in nursing homes, where pharmacological treatments should have greater control than in the case of non-institutionalised elderly patients (non-IEP).

Purpose To compare the prevalence of PIP between institutionalised elderly patients (IEP) and non-IEP admitted to a thirdlevel hospital at the moment of admission, and to identify the most inadequately prescribed pharmacological groups in those patients by using STOPP/START criteria.

Material and methods A retrospective, observational study was conducted in elderly patients over 80 years' old. A random sample of 218 patients was taken from a population of the total of elderly patients admitted to the Geriatric Unit of the hospital in 2017. A review of the medical discharge reports was carried out to obtain the patient demographic characteristics, number of prescribed drugs and PIP identified at the moment of admission. PIPs were classified according to STOPP/START criteria (2014 version).

Results Two-hundred and eighteen patients were included $(70.5 \%$ females) with a median age of $94(\mathrm{SD}=3.4)$. An average of 8.8 prescribed drugs/patient $(S D=3.2)$ was found. $92.3 \%$ of the patients had at least one PIP at admission, higher than the percentage found in similar studies $\left(76.8 \%{ }^{1}\right)$.

Average of $2.9 \mathrm{PIP} /$ patient: $2.8 \mathrm{PIP} /$ non-IEP $(\mathrm{SD}=1.8)$ and 3.2 PIP/IEP $(\mathrm{SD}=1.5)$, resembling data observed in other studies: $2.9 \mathrm{PIP} /$ non-IEP, $^{2}$ and $3.5 \mathrm{PIP}$ IEP. $^{3}$

$84.4 \%$ of patients had at least one STOPP criteria, a higher rate than obtained in other studies $\left(54.4^{4 \%}-58 \%{ }^{5}\right)$. The most frequent drugs were drugs without indication and central nervous system drugs that can cause falls.

$40.4 \%$ of patients had at least one START criteria, similar to the percentage found in the literature $\left(44.5^{4 \%}-46 \%{ }^{5}\right)$. The omission of cardiovascular system drugs and calcium and vitamin D supplements in patients with osteoporosis were the most prevalent.

Conclusion There is a high prevalence of PIP in elderly patients admitted to hospital regardless of where they come from (nursing homes or their own home). A higher control of prescriptions appears to be needed in nursing homes.

\section{REFERENCES AND/OR ACKNOWLEDGEMENTS}

1. Martin JH et al. (2018) http://dx.doi.org/10.1136/ejhpharm-2017-001262

2. Ahmad A, et al. (2014) DOl:10.2147/PPA.S48357

3. Finkers $\mathrm{F}$ et al. (2007) DOl:10.1111/j.1365-2710.2007.00849x

4. Bo M, et al. (2018) DOl:10.1111/ggi.13542

5. Argoullon L, et al. (2018) DOI:10.1684/pnv.2018.0726

No conflict of interest.

\section{PSQ-144 MEDICATION RECONCILIATION PROGRAMME PERFORMED IN A GENERAL AND DIGESTIVE SURGERY SERVICE}

C Mondelo-Garcia*, JM Gutiérrez Urbón, L Margusino Framiñán, MI Martín Herranz. Instituto de Investigación Biomédica de A Coruña Inibic. Complexo Hospitalario Universitario A Coruña Chuac. Sergas. Universidade da Coruña UDC., Pharmacy Service, A Coruña, Spain

\subsection{6/ejhpharm-2019-eahpconf.577}

Background Care transitions are critical points regarding medications errors because of the high number of treatment modifications that are carried out. Medication reconciliation (MR) and providing accurate information to the patients about their treatment can help prevent medication errors and consequently improve quality of care.

Purpose Our objective was to analyse discrepancies found between patients' current medication and treatments prescribed during hospitalisation to reduce these through the intervention of the hospital pharmacist.

Material and methods Prospective study from 1 June to 1 October 2018. Patients admitted to the General and Digestive Surgery Service of a university hospital during the study period who met all the inclusion criteria ( $>65$ years' old and $>4$ current medications as home treatment). At admission, the hospital pharmacist reviewed the patient's electronic medical records and interviewed the patient or the primary caregiver to obtain the accurate list of current medication. The hospital pharmacist contacted the physician to solve discrepancies which were classified in: omission, duplicity, wrong dose and wrong pharmaceutical form. Medications involved were classified according to the ATC classification. Patients who accepted, received written information about their treatment at discharge and answered a satisfaction survey. This study has been approved by the regional clinical research ethics committee.

Results Patients included: 127, 65 males (51.2\%). Median age (range):80.1 (66.0-93.3). Mean hospitalisation time \pm SD: 11.7 \pm 9.5 days. Median of medicines number as home treatment/ patient (range): 7 (5-14). Median of discrepancies found at admission/patient (range): $2(0-4): 10$ patients $(7.9 \%)$ did not present any discrepancy. Discrepancies classification $(n=214)$ : 196 omission (91.6\%), 14 wrong dose (6.5\%), three wrong pharmaceutical forms (1.4\%) and one duplicate (0.5\%). Discrepancies solved: 108 (50.8\%). Among 106 unsolved discrepancies, 47 (44.3\%) were omissions of lipid-lowering agents in primary prevention which were not usually prescribed during admission. Main ATC group with discrepancies: 116 cardiovascular system medications $(54.2 \%)$, followed by 25 of the nervous system (11.7\%). Satisfaction survey evaluation (67 patients): $8.6 / 10$ points.

Conclusion MR is an is an effective measure to reduce medication discrepancies. Hospital pharmacist intervention identified discrepancies, improving the quality of prescription during admission. Most unsolved discrepancies were statins in primary prevention. Cardiovascular and nervous system were the ATC groups with the most discrepancies. Patients report a high satisfaction rate.

\section{REFERENCES AND/OR ACKNOWLEDGEMENTS}

This study has been carried out with the support of Fundación Profesor Novoa Santos.

No conflict of interest. 